\title{
SUPPRESSION OF SODIUM EXCRETION BY THE COLON IN \\ CONGESTIVE HEART FAILURE AND CIRRHOSIS OF \\ THE LIVER DEMONSTRATED BY THE USE OF CATION EXCHANGE RESINS ${ }^{1}$
}

\author{
By EUGENE Y. BERGER AND J. MURRAY STEELE with THE techNical assistaNCE of \\ MARY A. HOMER AND GERTRUDE P. QUINN \\ (From the Research Service [NYU Medical Division], Goldwater Memorial Hospital, Wel- \\ fare Island, New York, and the Department of Medicine, New York University \\ College of Medicine, New York, N. Y.)
}

(Submitted for publication November 14, 1951; accepted March 3, 1952)

Evidence for a hormonal disturbance in those diseases in which the accumulation of edema fluid is a major clinical manifestation has, until recently, been meager and the conclusions doubtful. Thorn and Emerson (1), in 1940, observed the exacerbation of ascites and edema during the premenstrual period in a patient with glomerulonephritis and in a patient with cirrhosis of the liver which suggests that gonadal hormones may at least affect the course of edema in these diseases. In 1942 Futcher and Schroeder (2), in their demonstration of the impaired excretion of sodium chloride in congestive heart failure, suggested that the cause might be increased venous pressure or renal anoxia or "an endocrine mechanism possibly involving the adrenal cortex."

In the last two years more substantial, although indirect, evidence for a hormonal disturbance in edematous states has been forthcoming. Parrish (3) found in four of 10 patients with congestive heart failure increased excretion of urinary corticoids which prolonged the life of adrenalectomized rats. Deming and Luetscher (4) report greatly increased sodium-retaining activity (by a bioassay method) in the urine of patients with massive edema due to nephrosis or heart failure. Albert and Smith (5), following the administration of ACTH, desoxycorticosterone, or cortisone to normal individuals, found in five subjects who developed marked peripheral edema all the hemodynamic changes of heart failure, except a decreased cardiac output.

The present investigation affords further evidence of a hormonal disturbance in certain diseases in which edema fluid accumulates. It is

1 This investigation was supported in part by the Public Health Research Institute of the City of New York, and by Smith, Kline \& French Laboratories. well known that desoxycorticosterone diminishes the excretion of sodium by the kidney and the sweat gland (6) and recently it has been demonstrated that desoxycorticosterone also diminishes the excretion of sodium by the salivary gland and the colon (7). There is evidence that the sweat and salivary glands in the patient who is accumulating edema act in a fashion which resembles excessive desoxycorticosterone-like activity $(8,9)$. This study was designed to ascertain whether the colon of the edematous patient also acts in a fashion which resembles excessive desoxycorticosterone-like activity.

The concentration of sodium in the sweat and saliva is normally of sufficient magnitude to permit measurement of a possible decrease. It is, however, difficult to document a decrease in the excretion of fecal sodium because the amount of fecal sodium is normally quite small and variable (10). In order to insure sufficient amounts of sodium in the stool to be able to quantify a difference between the normal individual and the edematous patient, a cation exchange resin was fed (11). For proper interpretation of the data, the mechanics of the action of the resin in relation to sodium in the lumen of the gut must be considered (7). The exchange of ions on the surface of the resin is almost immediate and the pattern of electrolytes on its surface is dependent on the number and nature of the electrolytes in the surrounding medium $(12,13)$. In the small intestine the resin is in equilibrium with a solution containing about $140 \mathrm{mEq}$ of sodium per liter. When more sodium ions leave the lumen of the gut than enter, such as occurs in the colon, there is a net reabsorption of sodium. In proportion to the other ions present, there are fewer sodium ions available for the resin in the lumen of the colon 
than in the lumen of the small intestine and a new equilibrium is established in the colon between the sodium on the resin and that in solution in the colonic contents. The balance between the transfers of sodium across the colonic mucosa and the "attraction" of the resin for the sodium eventually determines how much sodium is retained on the resin and hence the amount of sodium appearing in the stool. The net transfer (i.e., eventual reabsorption) of sodium across the colonic mucosa in the normal individual may thus be compared with the net transfer in the edematous individual by a comparison of the amounts of sodium removed by the resin in the stool.

The patients who were studied were selected as representative of the severest type of sodium retention. The criterion by which patients were selected was that the daily urinary excretion of sodium was negligible in relation to the dietary intake. Of course there are edematous patients who gain weight from day to day and who excrete more sodium than the patients studied. Their weight gain is correspondingly slower. For example, if a patient ingests 5 grams of sodium daily and excretes only 2 , he would then regularly gain weight, but if the intake is reduced to 1 gram, the patient will no longer accumulate fluid and might even lose weight by diuresis. Presumably in patients who are able to excrete a moderate amount of sodium in the urine the excretion of sodium by the colon, salivary gland, and the sweat gland is not sufficiently impaired to demonstrate a difference from the rather wide range of normal values. Patients whose urinary sodium excretion was severely limited were therefore selected for study in order to demonstrate a difference from the normal.

\section{PROCEDURES}

A cation exchange resin was fed to two groups of patients. The first, considered the control group, consisted of patients who were suffering from a variety of chronic diseases without evident disturbance in their water balance. The second group consisted of patients who were actively accumulating edema fluid because of congestive heart failure or cirrhosis of the liver. Both groups received the same regular ward diet without the privilege of adding salt. The edematous patients never excreted more than 5 and usually excreted less than 1 $\mathrm{mEq}$ of sodium per day in the urine. The plasma sodium concentration in these edematous patients was essentially normal (135 to $140 \mathrm{mEq}$ per liter) except for one patient (CER, Table I), whose plasma sodium ranged from 128 to $132 \mathrm{mEq}$ per liter.

Forty-five grams of carboxylic resin in the ammonium form or in a combination of the potassium and ammonium forms (ratio of one part of potassium to two of ammonium) were fed daily to both groups. Stools were collected and analyzed for sodium, potassium, and nitrogen. To make certain that samples of stool were representative of the period of feeding resin, analyses were not begun until four days after beginning resin therapy. The study was conducted on the wards of a chronic disease hospital and it was quite difficult to insure complete stool collections. For this reason, fecal sodium and potassium were expressed in terms of excreted nitrogen. The daily fecal nitrogen was assumed to be the same for both groups of patients since they were on the same diet. This mode of expression avoids the errors of incomplete stool collections and erratic bowel movements but does contain the error of the variability in fecal nitrogen excretion (14). The latter error was thought to be smaller under the circumstances of the investigation. In order to use units which were in some way representative of the daily fecal excretion of sodium and potassium the data have been expressed in $\mathrm{mEq}$ of sodium or potassium per gram of nitrogen.

Stools were dried under infra red light. Triplicate aliquots of the dried feces were treated with concentrated sulfuric acid and ashed in platinum crucibles at $700^{\circ} \mathrm{C}$. The ash was dissolved in hydrochloric acid and analyzed for sodium and potassium. Separate aliquots of the dried feces were analyzed for nitrogen and ammonium. All nitrogen values have been corrected for ammonium and represent ammonium-free nitrogen.

Sweat was collected in rubber gloves. The gloves and arms were prepared according to the procedure suggested by Leslie and Levin (15). The patient was attired in hospital pajamas and covered with two woolen blankets. The lower extremities were placed in a whirlpool bath at $42^{\circ} \mathrm{C}$. After a 20 to 40 minute immersion in the bath the gloves were removed and the accumulated sweat poured into a vial.

Saliva was collected in the following manner. The mouth was first rinsed with distilled water and the subject was given paraffin to chew. The saliva collected during the first minute's chewing was discarded. Two separate samples were taken in the second and third minutes. The values reported are the means of the sodium content of these two samples.

Sodium and potassium were determined with an internal standard flame photometer (16). Nitrogen was determined by the micro-Kjeldahl procedure and ammonium was determined according to Summerson's modification of the Van Slyke and Cullen procedure (17).

\section{OBSERVATIONS}

In the control group of eight patients without evident disturbance in their degree of hydration who received carboxylic resin, the mean fecal so- 
TABLE I

Fecal excretion of sodium and potassium during resin administration Comparison of the normal with the edematous patient

\begin{tabular}{|c|c|c|c|c|c|c|c|c|c|c|}
\hline \multicolumn{5}{|c|}{ Normal } & \multicolumn{6}{|c|}{ Edematous } \\
\hline Pt. & Resin form & No. obs. & Sodium & Potassium & Pt. & Diałnosis† & Resin form & No. obs. & Sodium & Potassium \\
\hline $\begin{array}{l}\text { CNT } \\
\text { CHG } \\
\text { AST } \\
\text { KRS } \\
\text { KRS } \\
\text { CRW } \\
\text { LST } \\
\text { BRD } \\
\text { CHE } \\
\text { LST }\end{array}$ & $\begin{array}{c}\mathrm{NH}_{4} \\
\mathrm{NH}_{4} \\
\mathrm{NH}_{4} \\
\mathrm{NH}_{4} \\
\mathrm{~K} \cdot \mathrm{NH}_{4} \\
\mathrm{NH}_{4} \\
\mathrm{NH}_{4} \\
\mathrm{NH}_{4} \\
\mathrm{NH}_{4} \\
\mathrm{~K} \cdot \mathrm{NH}_{4}\end{array}$ & $\begin{array}{r}9 \\
10 \\
8 \\
7 \\
7 \\
6 \\
6 \\
3 \\
7 \\
7\end{array}$ & $\begin{array}{r}m E q / \\
\operatorname{gram} \mathbf{N} * \\
25.3 \\
26.3 \\
33.2 \\
38.0 \\
40.2 \\
52.8 \\
53.2 \\
59.2 \\
63.9 \\
64.2\end{array}$ & $\begin{array}{r}m E q / \\
g r a m N^{*} \\
65.4 \\
42.7 \\
53.3 \\
53.5 \\
74.4 \\
90.0 \\
53.1 \\
144.0 \\
69.8 \\
61.3\end{array}$ & $\begin{array}{l}\text { FAG } \\
\text { HAM } \\
\text { FAG } \\
\text { STP } \\
\text { HEN } \\
\text { POL } \\
\text { CER } \\
\text { OST } \\
\text { POL } \\
\text { KNS }\end{array}$ & $\begin{array}{l}\mathrm{CL} \\
\mathrm{CHF} \\
\mathrm{CL} \\
\mathrm{CHF} \\
\mathrm{CL} \\
\mathrm{CHF} \\
\mathrm{CHF} \\
\mathrm{CHF} \\
\mathrm{CHF} \\
\mathrm{CHF}\end{array}$ & $\begin{array}{c}\mathrm{K} \cdot \mathrm{NH}_{4} \\
\mathrm{NH}_{4} \\
\mathrm{NH}_{4} \\
\mathrm{~K} \cdot \mathrm{NH}_{4} \\
\mathrm{NH}_{4} \\
\mathrm{~K} \cdot \mathrm{NH}_{4} \\
\mathrm{NH}_{4} \\
\mathrm{NH}_{4} \\
\mathrm{NH}_{4} \\
\mathrm{NH}_{4}\end{array}$ & $\begin{array}{r}2 \\
3 \\
4 \\
2 \\
16 \\
2 \\
2 \\
1 \\
3 \\
15\end{array}$ & $\begin{array}{c}\underset{g r q}{\operatorname{mram} \mathrm{N}^{*}} \\
12.2 \\
13.4 \\
14.5 \\
15.4 \\
20.0 \\
20.5 \\
20.8 \\
22.1 \\
24.7 \\
25.9\end{array}$ & $\begin{array}{r}\underset{m E q}{m} \mathbf{m} \\
\text { gram } \mathrm{N}^{*} \\
54.3 \\
121.7 \\
33.8 \\
31.0 \\
61.8 \\
97.8 \\
80.2 \\
38.2 \\
57.5 \\
67.6\end{array}$ \\
\hline \multicolumn{3}{|c|}{$\begin{array}{l}\text { Mean } \\
\text { Standard deviation }\end{array}$} & $\begin{array}{r}45.6 \\
\pm 14.9\end{array}$ & $\begin{array}{r}70.8 \\
\pm 29.0\end{array}$ & \multicolumn{4}{|c|}{$\begin{array}{l}\text { Mean } \\
\text { Standard deviation }\end{array}$} & $\begin{array}{r}19.0 \\
\pm 4.8\end{array}$ & $\begin{array}{r}64.3 \\
\pm 29.1\end{array}$ \\
\hline
\end{tabular}

* Mean of stated number of observations.

$+\mathrm{CHF}$, Congestive heart failure; CL, Cirrhosis of the liver.

dium excretion of 10 sets of observations was $45.6 \pm 14.9 \mathrm{mEq}$ per gram of nitrogen (Table I). In the group of eight patients who were accumulating edema fluid because of cirrhosis of the liver or congestive heart failure, the mean sodium excretion of 10 sets of observations was $19.0 \pm 4.8$ $\mathrm{mEq}$ per gram of nitrogen. The values for the fecal excretion of sodium were essentially the same in a given individual whether he was receiving the ammonium resin or the ammonium-potassium mixture (KRS, LST, FAG, POL, Table I). The data indicate that under similar conditions of diet and resin administration the net transfer of sodium from the lumen of the colon to the surrounding blood stream is greater in the edematous patient than in the normal. The resin is consequently less effective in retaining sodium in the stool in the edematous patient than in the normal patient.

The mean fecal excretion of potassium was approximately the same in the control group and the edematous group. The amounts of potassium excreted seemed to have little relation to the amounts of sodium excreted. In a given individual, however, somewhat more potassium was excreted in the stool when potassium was incorporated in the resin (KRS, LST, FAG, POL, Table I).

Sodium excretion by the sweat and salivary glands was measured in three patients of the group who were accumulating edema. Two patients were suffering from congestive heart failure and one from cirrhosis of the liver. In each patient the concentration of sodium in the sweat and saliva was much reduced as compared to normal values (Figure 1). In 10 samples of hand sweat in seven normal individuals taken at various times, the mean concentration of sodium was $39 \mathrm{mEq}$ per liter, range 15 to $75 \mathrm{mEq}$ per liter. In two patients accumulating edema fluid, the concentration of sodium in the sweat was 8 and $13 \mathrm{mEq}$ per liter. In 30 samples of saliva taken at various times in nine normal individuals, the mean concentration of sodium was $35 \mathrm{mEq}$ per liter, range 10 to $61 \mathrm{mEq}$ per liter, whereas in the three edematous individuals the concentrations of sodium in the saliva were 8,7 , and $5 \mathrm{mEq}$ per liter. The data are few but are in agreement with similar

COMPARISON OF THE NORMAL $\leadsto$ WITH THE EDEMATOUS PATIENT $\leadsto$

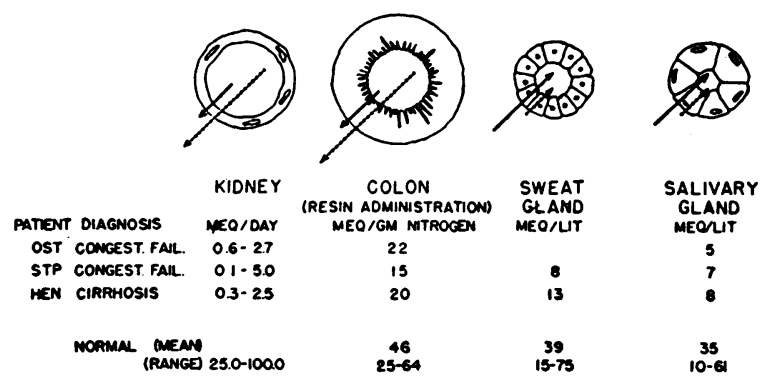

Fig. 1. Net Sodium Transfer 
data in the literature $(8,9,18)$ and are presented only to have measurements in the same patient who fails to excrete expected amounts of sodium in the stool. The edematous patient, then, as compared to the normal, alters the transfer of sodium by various organs, the kidney, the colon, the sweat and salivary glands, in such a fashion as to limit the loss of sodium from the body.

\section{DISCUSSION}

The accumulation of edema in those patients who continually gain weight from day to day is due chiefly to the retention of sodium, chloride, and water ingested by the patient and not excreted by the kidney. The primary difficulty appears to be the retention of sodium. A disturbance in water excretion does not seem to be the basic difficulty. Although the patient with congestive heart failure or cirrhosis of the liver may eliminate a test dose of water more slowly than the normal individual (19-21), drinking large amounts of water daily does not aggravate the edema of congestive heart failure (22). Nor does it appear that the kidney has any difficulty in excreting the chloride ion as the edematous patient can excrete ammonium, potassium, or calcium chloride easily and sometimes with an increased amount of water (23). However, the urine of the patient who is actively accumulating edema fluid such as the type of patient reported here, contains only small amounts of sodium irrespective of the amount or form of sodium ingested. Under normal circumstances the kidney regulates the sodium content of the body by balancing the output against the intake. Why the kidney fails to do so in certain diseases is a point of controversy.

Many factors are known to affect the renal excretion of sodium. Alterations in filtration rate (24), renal arterial and venous pressure (25-27), oxygen tension (28), and plasma volume (29) are factors which have been investigated as individual entities and have been demonstrated to influence the renal excretion of sodium. The controversy resides in the relative importance of these factors and in the manner in which they play a role in the development of edema. The disturbed cardiovascular dynamics found in congestive heart failure are absent in cirrhosis of the liver, and the renal plasma flow and glomerular filtration rate are within normal limits (30). Nevertheless, in both these diseases where the patient is actively accumulating fluid there is evidence that several organs act to suppress the excretion of sodium. It is not to be inferred that organs other than the kidney contribute to any great extent to the accumulation of edema in congestive heart failure and cirrhosis of the liver. The data serve only to illustrate the fact that the suppression of the excretion of sodium in these diseases is a phenomenon which is common to various organs.

The fact that desoxycorticosterone has the ability to induce a similar disturbance in the transfer of sodium across the kidney, colon, salivary and sweat glands, suggests that the accumulation of edema in both cirrhosis of the liver and congestive heart failure is due, at least in part, to an excess of desoxycorticosterone-like hormone or to a deficiency of a possible antagonist. Desoxycorticosterone-like activity occurs as a normal physiological process when there are excessive losses of sodium from the body or when the dietary intake of sodium is sharply restricted (31-33) and is manifested by limiting the excretion of sodium from the body by several organs. The diminished excretion of sodium found in diseases where there is active accumulation of edema fluid resembles the normal mechanism for the conservation of salt. The question is why the normal mechanism for limiting the escape of sodium from the body goes awry in these diseases. It is not known whether the biochemical stimulus is the same for the normal conservation of salt as it is in congestive heart failure and cirrhosis of the liver or whether it is the same or different for these diseases. It is clear that in these edematous states four organs, across which the transfer of sodium can be measured, act in concert to limit the escape of sodium from the body. The accumulation of edema in these widely divergent clinical states would seem then to be due in part to a disturbance in hormonal balance.

\section{CONCLUSIONS}

With the use of cation exchange resin it has been demonstrated that the colon of the edematous patient retains sodium to a greater degree than the colon of the normal subject. This suppression of sodium excretion is part of a generalized phe- 
nomenon involving the kidney, sweat gland and salivary gland. The inference is drawn that the accumulation of edema in congestive heart failure and cirrhosis of the liver is at least partly mediated through a disturbance in the hormonal control of sodium excretion.

\section{ACKNOWLEDGMENTS}

The authors wish to thank Dr. Cecilio Putong, Jr., and Dr. Edward T. Johnson for their assistance in the collection of sweat samples.

\section{REFERENCES}

1. Thorn, G. W., and Emerson, K., Jr., Role of gonadal and adrenal cortical hormones in the production of edema. Ann. Int. Med., 1940, 14, 757.

2. Futcher, P. H., and Schroeder, H. A., Studies on congestive heart failure. II. Impaired renal excretion of sodium chloride. Am. J. M. Sc., 1942, 204, 52.

3. Parrish, A. E., The bioassay of adrenal corticoids in the urine of patients with congestive heart failure. J. Clin. Invest., 1949, 28, 45.

4. Deming, Q. B., and Luetscher, J. A., Jr., Increased sodium-retaining corticoid excretion in edema, with some observations on the effects of cortisone in nephrosis. J. Clin. Invest., 1950, 29, 808.

5. Albert, R. E., and Smith, W. W., The hemodynamic effects of ACTH, DCA and cortisone compared with congestive heart failure. Am. J. Med., 1952, $12,111$.

6. Conn, J. W., Electrolyte composition of sweat. Arch. Int. Med., 1949, 83, 416.

7. Berger, E. Y., Quinn, G. P., and Homer, M. A., Effect of desoxycorticosterone on the colon: its relation to the action of cation exchange resins in man. Proc. Soc. Exper. Biol. \& Med., 1951, 76, 601.

8. White, A. G., Gordon, H., and Leiter, L., Studies in edema. II. The effect of congestive heart failure on saliva electrolyte concentrations. J. Clin. Invest., 1950, 29, 1445.

9. Eisenmenger, W. J., Blondheim, S. H., Bongiovanni, A. M., and Kunkel, H. G., Electrolyte studies on patients with cirrhosis of the liver. J. Clin. Invest., 1950, 29, 1491.

10. Clark, G. W., Studies in the mineral metabolism of adult man, quoted by Shohl, A. T., in Mineral Metabolism. Reinhold Pub. Corp., New York, 1939, p. 333.

11. Irwin, L., Berger, E. Y., Rosenberg, B., and Jackenthal, R., The effect of a cation exchange resin on electrolyte balance and its use in edematous states. J. Clin. Invest., 1949, 28, 1403.
12. Bauman, W. C., and Eichhorn, J., Fundamental properties of a synthetic cation exchange resin. J. Am. Chem. Soc., 1947, 69, 2830.

13. Kunin, R., Ion exchange. Analyt. Chem., 1949, 21, 87.

14. Toscani, V., and Whedon, G. D., Nitrogen loss in feces: the variability of excretion in normal subjects on constant dietary intakes. J. Nutrition, 1951, 45, 119.

15. Leslie, A., and Levin, M. H., Sweat test simplified for clinical use. Am. J. Med., 1950, 8, 823.

16. Barnes, R. B., Richardson, D., Berry, J. W., and Hood, R. L., Flame photometry-a rapid analytical procedure. Indust. \& Engin. Chem., Analyt. Ed., 1945, 17, 605.

17. Hawk, P. B., Oser, B. L., and Summerson, W. H., Practical Physiological Chemistry. Blakiston Co., Philadelphia, 1947, Ed. 12, p. 828.

18. Merrill, A. J., Mechanisms of salt and water retention in heart failure. Am. J. Med., 1949, 6, 357.

19. Fremont-Smith, F., Fremont-Smith, M., Dailey, M. E., Solomon, P., Stetten, DeW., Jr., and Carroll, M. P., Studies in Edema. I. The mechanism of water diuresis in man. J. Clin. Invest., 1930, 9, 7.

20. Fremont-Smith, F., The mechanism of edema formation. New England J. Med., 1932, 206, 1286.

21. Ralli, E. P., Leslie, S. H., Stueck, G. H., Jr., and Laken, B., Studies of the serum and urine constituents in patients with cirrhosis of the liver during water tolerance tests. Am. J. Med., 1951, 11, 157 .

22. Schemm, F. R., A high fluid intake in the management of edema, especially cardiac edema. II. Clinical observations and data. Ann. Int. Med., 1944, $21,937$.

23. Goodman, L., and Gilman, A., The Pharmacological Basis of Therapeutics. Macmillan Co., New York, 1941, Chap. 35.

24. Berliner, R. W., Renal excretion of water, sodium, chloride, potassium, calcium, and magnesium. Am. J. Med., 1950, 9, 541.

25. Blake, W. D., Wégria, R., Keating, R. P., and Ward, $H$. P., Effect of increased venous pressure on renal function. Am. J. Physiol., 1949, 157, 1.

26. Farber, S. J., Alexander, J. D., and Eichna, L. W., Renal hemodynamics and salt and water excretion during induced congestion of the inferior vena cava of man. J. Clin. Invest., 1951, 30, 638.

27. Selkurt, E. E., Effect of pulse pressure and mean arterial pressure modification on renal hemodynamics and electrolyte and water excretion. Circulation, 1951, 4, 541.

28. Berger, E. Y., Galdston, M., and Horwitz, S. A., The effect of anoxic anoxia on the human kidney. J. Clin. Invest., 1949, 28, 648.

29. Welt, L. G., and Orloff, J., The effects of an increase in plasma volume on the metabolism and excre- 
tion of water and electrolytes by normal subjects. J. Clin. Invest., 1951, 30, 751.

30. Epstein, F. H., Lesser, G. T., and Berger, E. Y., Renal function in decompensated cirrhosis of the liver. Proc. Soc. Exper. Biol. \& Med., 1950, 75, 822.

31. Daly, C., and Dill, D. B., Salt economy in humid heat. Am. J. Physiol., 1937, 118, 285.
32. McCance, R. A., The effect of salt deficiency in man on the volume of the extracellular fluids, and on the composition of sweat, saliva, gastric juice and cerebrospinal fluid. J. Physiol., 1938, 92, 208.

33. Conn, J. W., The mechanism of acclimatization to heat, in Advances in Internal Medicine, edited by Dock, W., and Snapper, I. Interscience Publishers, Inc., New York, 1949, Vol. III, p. 373. 